Columbia Law School

Scholarship Archive

\title{
Moral Disengagement Among Serious Juvenile Offenders: A Longitudinal Study of the Relations between Morally Disengaged Attitudes and Offending
}

\author{
Jeffrey Fagan \\ Columbia Law School, jfagan@law.columbia.edu \\ Elizabeth P. Shulman \\ eshulman@uci.edu \\ Elizabeth Cauffman \\ cauffman@uci.edu \\ Alex R. Piquero \\ apiquero@utdallas.edu
}

Follow this and additional works at: https://scholarship.law.columbia.edu/faculty_scholarship

Part of the Juvenile Law Commons, and the Law and Psychology Commons

\section{Recommended Citation}

Jeffrey Fagan, Elizabeth P. Shulman, Elizabeth Cauffman \& Alex R. Piquero, Moral Disengagement Among Serious Juvenile Offenders: A Longitudinal Study of the Relations between Morally Disengaged Attitudes and Offending, DeVelopmental Psychology, Vol. 47, P. 1619, 2011; Columbia Public LaW Research Paper No. 11-280 (2011).

Available at: https://scholarship.law.columbia.edu/faculty_scholarship/1706

This Working Paper is brought to you for free and open access by the Faculty Publications at Scholarship Archive. It has been accepted for inclusion in Faculty Scholarship by an authorized administrator of Scholarship Archive. For more information, please contact scholarshiparchive@law.columbia.edu. 


\title{
Columbia Law School
}

Public Law \& Legal Theory Working Paper Group

Paper Number 11 - 280

Moral Disengagement Among Serious Juvenile Offenders:

A Longitudinal Study of the Relations Between Morally

Disengaged Attitudes and Offending

Elizabeth P. Shulman and Elizabeth Cauffman

University of California, Irvine

\author{
Alex R. Piquero \\ University of Texas at Dallas
}

and

Jeffrey Fagan

Columbia University

September 25, 2011 


\title{
Moral Disengagement Among Serious Juvenile Offenders: A Longitudinal Study of the Relations Between Morally Disengaged Attitudes and Offending
}

\author{
Elizabeth P. Shulman and Elizabeth Cauffman \\ University of California, Irvine
}

\author{
Alex R. Piquero \\ University of Texas at Dallas
}

\author{
Jeffrey Fagan \\ Columbia University
}

\begin{abstract}
The present study investigates the relation between moral disengagement-one's willingness to conditionally endorse transgressive behavior-and ongoing offending in a sample of adolescent male felony offenders $(N=1,169)$. In addition, the study attempts to rule out callous-unemotional traits as a third variable responsible for observed associations between moral disengagement and offending. A bivariate latent change score analysis suggests that reduction in moral disengagement helps to speed decline in self-reported antisocial behavior, even after adjusting for the potential confound of callous-unemotional traits. Declines in moral disengagement are also associated with declining likelihood of offending, based on official records. Given that both moral disengagement and offending tend to decrease over time, these findings suggest that changing attitudes toward antisocial behavior contribute to desistance from offending among delinquent youth.
\end{abstract}

Keywords: moral disengagement, juvenile offending, adolescence, callous-unemotional traits, longitudinal

Adolescence is a developmental epoch characterized by important physical, social and psychological changes. It is a time of questioning social and moral norms (Kohlberg \& Gilligan, 1971), and for some, violating them; rates of antisocial behavior peak during this period (Hirschi \& Gottfredson, 1983; Piquero, 2008; Piquero, Farrington, \& Blumstein, 2003). One potential contributor to this developmental pattern is the extent to which individuals view antisocial acts as acceptable or justifiable. The present study examines the role of attitudes toward antisocial behavior-moral disengagement-in desistance from offending among delinquent

Elizabeth P. Shulman and Elizabeth Cauffman, Department of Psychology and Social Behavior, School of Social Ecology, University of California, Irvine; Alex R. Piquero, Criminology, School of Economic, Political, and Policy Sciences, University of Texas at Dallas; Jeffrey Fagan, Law and Epidemiology, Columbia University.

The research project was funded by grants from the Office of Juvenile Justice and Delinquency Prevention, National Institute of Justice, John D. and Catherine T. MacArthur Foundation, William T. Grant Foundation, Robert Wood Johnson Foundation, William Penn Foundation, Centers for Disease Control, National Institute on Drug Abuse (Grant R01DA019697), Pennsylvania Commission on Crime and Delinquency, and the Arizona Governor's Justice Commission. We are grateful for their support. This paper's content is solely the responsibility of the authors and does not necessarily represent the views of these agencies.

Correspondence concerning this article should be addressed to Elizabeth P. Shulman, Psychology and Social Behavior, School of Social Ecology, University of California, Irvine, Irvine, CA 92697-7050. E-mail: eshulman@uci.edu youth. We address this question in a sample of adolescent felony offenders interviewed twice a year for 3 years.

\section{Moral Disengagement}

The social-cognitive theory of moral agency (Bandura, 1986, 1999) proposes that the reason that most people refrain from transgressing most of the time is that they have internalized society's standards of conduct. Therefore, acts of wrongdoing risk not only external sanctions (e.g., disapproval, exclusion, arrest, punishment) but also internal sanctions (e.g., shame, remorse, damage to one's self-concept). The theory argues that to avoid internal sanctions, people construct justifications for behaviors that violate moral standards, a process called moral disengagement. For example, a person contemplating stealing a video game might tell him or herself that no one is really hurt by the act or that video game companies deserve to have their merchandise stolen because they price it too high. By cognitively reconstruing an antisocial act to make it seem less wrong or even not wrong, one can circumvent-or disengage - the internal emotional checks that usually prevent misconduct. Social cognitive theory suggests that moral disengagement facilitates all sorts of wrongdoing, from the very minor (e.g., illegally downloading music) to the very major (e.g., genocide).

Repeated instances of moral disengagement may lead to routinization of this process (Bandura, 1991). That is, individuals who frequently rationalize misbehavior may develop stably morally disengaged attitudes, characterized by general tolerance for moral 
violations ${ }^{1}$ or an "uncaring and rejecting attitude toward societal values" (Hyde, Shaw, \& Moilanen, 2010, p. 197). Individuals with morally disengaged attitudes perceive some types of antisocial behavior as reasonable or justified; for example, they may agree that "It is all right to fight when your group's honor is threatened" and "Some people deserve to be treated like animals" (two items on Bandura's Mechanisms of Moral Disengagement Scale).

Empirical evidence suggests that adolescents who more often endorse these views (i.e., score higher in moral disengagement) are more likely to engage in antisocial behavior. In studies of children and adolescents, this form of moral disengagement has been associated with aggression (Bandura, Barbaranelli, Caprara, \& Pastorelli, 1996; Pelton, Gound, Forehand, \& Brody, 2004), bullying (Gini, 2006; Hymel, Rocke-Henderson, \& Bonanno, 2005), and delinquency (Bandura et al., 1996; Bandura, Caprara, Barbaranelli, Pastorelli, \& Regalia, 2001; Pelton et al., 2004). Furthermore, this association does not appear to be an artifact of shared method variance; Bandura et al. (1996) reported medium to strong associations between (self-reported) moral disengagement and both peer and parent ratings of aggression among middle school students; and Gini (2006) noted substantially higher levels of moral disengagement among peer-nominated bullies compared to victims and students uninvolved in bullying. Much of the research on moral disengagement has focused on general adolescent samples and found moral disengagement to be an important risk factor for antisocial behavior in this population.

In addition, longitudinal research provides evidence that declines in moral disengagement may contribute to declining levels of antisocial behavior in the transition to adulthood. For example, a study that followed a community sample of youth in Italy from early adolescence into early adulthood found that levels of moral disengagement (or morally disengaged attitudes) were relatively high in early adolescence and, for most individuals (89\%), declined with age into early adulthood (Paciello, Fida, Tramontano, Lupinetti, \& Caprara, 2008). Furthermore, rates of antisocial behavior tracked levels of moral disengagement, with chronically aggressive youth exhibiting persistently high levels of moral disengagement and less aggressive youth exhibiting lower levels of moral disengagement. These findings provide evidence that in normative populations, high levels of moral disengagement may help sustain antisocial behavior, whereas declining levels may foster desistance.

\section{Moral Disengagement Among Delinquent Youth}

Identifying predictors of desistance versus persistence in antisocial behavior among delinquent youth is a salient concern for both theory and policy (Laub \& Sampson, 2001). Understanding what leads to these different outcomes among adolescent offenders could assist juvenile justice practitioners in distinguishing the small percentage of youthful offenders who will persist in crime from the majority who will (largely) abandon it (Mulvey et al., 2004). Given the evidence of greater antisocial behavior among those prone to moral disengagement (e.g., Bandura et al., 1996, 2001; Gini, 2006; Paciello et al., 2008; Pelton et al., 2004), it seems likely that moral disengagement may predict ongoing antisocial behavior among delinquent youth. Though no studies have conducted comparisons of moral disengagement between demographically matched samples of delinquent and nondelinquent youth, Kiriakidis (2008) reported higher average levels of moral disengagement in a sample of youthful male offenders (ages 1621) than those found in a community sample of middle school students (Bandura et al., 1996). However, the present study is the first, to our knowledge, to examine the relations between moral disengagement and offending among delinquent youth over time. We predict that, as in normative samples of adolescents, morally disengaged attitudes will facilitate antisocial behavior in this population.

\section{Callous-Unemotional Traits: A Confound on the Moral Disengagement-Offending Link?}

As noted above, the theory of moral disengagement presumes that individuals have the capacity to experience negative social emotions such as shame or remorse. In examining the impact of moral disengagement on offending in a sample of delinquent youth, we felt it important to consider the possibility that a nontrivial portion of the sample might evince some level of socioemotional dysfunction in the form of callous-unemotional (CU) traits. Callous individuals, who have attenuated experiences of shame, remorse, empathy, and other social emotions, have been found to exhibit low fearfulness and insensitivity to punishment (O'Brien \& Frick, 1996; Pardini, Lochman, \& Frick, 2003). These characteristics are thought to interfere with the development of conscience (Salekin \& Frick, 2005) and the internalization of moral standards of behavior (Blair, 2007; Dienstbier, 1984; Kochanska, 1991). Critically, it appears that callous individuals are not as able as others to feel that an act is wrong (Blair, 2007). This deficiency in the ability to respond emotionally to planned or completed moral violations means that relatively callous youths are likely to exhibit permissive attitudes toward wrongdoing, especially when confronted with a potential justification for the act. Consequently, callous youths are likely to score high on the measure of moral disengagement used in most research on the topic (including the present study), which asks youths whether they agree with justifications for various moral violations. Indeed, Hyde et al. (2010) found that lower empathy (i.e., higher callousness) at age 12 predicts greater moral disengagement at age 15 .

Thus, we hypothesize that callousness will be associated with morally disengaged attitudes, as operationalized in this research. However, these attitudes among callous youths are not indicative of real moral disengagement. Relatively callous individuals, because they lack the emotional arsenal required for self-censure, would not need to morally disengage to commit antisocial acts. Real moral disengagement hinges on the presence of internal sanctions and the ability of an individual to feel shame, guilt, and empathy (Bandura, 1991). Only after repeated efforts to disengage these internal sanctions does routinized moral disengagement emerge, according to social-cognitive theory. Accordingly, we hypothesize that morally disengaged attitudes can arise through

\footnotetext{
${ }^{1}$ We view moral disengagement, as measured in this study, as an attitude or set of beliefs conceptually similar to techniques of neutralization (Sykes \& Matza, 1957), self-serving cognitive distortions (Gibbs, 1991; Barriga \& Gibbs, 1996), and normative beliefs about aggression (Guerra et al., 1994; Huesmann \& Guerra, 1997). For discussions of the conceptual similarity of moral disengagement and these other constructs, see Maruna and Copes (2005) and Barriga, Morrison, Liau, and Gibbs (2001).
} 
two separate pathways: (a) through repeated instances of disengaging internal sanctions via justification of wrongdoing (i.e., real moral disengagement), and (b) as a consequence of CU traits.

This issue is particularly salient when studying the relation between moral disengagement and antisocial behavior in a delinquent sample, which may be more callous, on average, than the general population. Research on emotional functioning in delinquent youths finds that some-especially those with the most serious behavior problems-have attenuated (or absent) experiences of social emotions (Caputo, Frick, \& Brodsky, 1999; Christian, Frick, Hill, Tyler, \& Frazer, 1997; Frick \& White, 2008). Thus, our sample, which includes youths convicted of felony offenses, is likely to exhibit elevated levels of CU traits.

We view callousness as etiologically distinct from routinized moral disengagement. Morally disengaged attitudes, which result from repeated instances of moral disengagement, are likely to emerge in response to mostly contextual factors, such as observing others engaging in misconduct, or social pressure to transgress (Bandura, 1991). Callousness, on the other hand, appears to have a substantial biological basis. Recent studies of twin pairs suggest that $\mathrm{CU}$ traits are highly heritable, with genetic contributions explaining $42 \%-43 \%$ of the variation in this characteristic (Larsson, Andershed, \& Lichtenstein, 2006; Taylor, Loney, Bobadilla, Iacono, \& McGue, 2003). Also, environmental factors, such as parenting, appear to be less strongly related to antisocial conduct among callous than among noncallous children (Oxford, Cavell, \& Hughes, 2003; Wootton, Frick, Shelton, \& Silverthorn, 1997).

In summary, we view callousness as conceptually and etiologically distinct from moral disengagement. However, because callousness has been linked to both moral disengagement and offending, it should be treated as a potential confound on the relations between the last two variables, especially in a sample that is likely to exhibit elevated levels of callousness. Yet prior research on moral disengagement and offending has not accounted for the effects of callousness. We address that omission in this research.

\section{Specific Aims and Plan of Analysis}

The present study addresses three specific aims. First, using a bivariate latent change score (LCS) model (McArdle, 2009; McArdle \& Hamagami, 2004), we investigate the longitudinal relations between moral disengagement and self-reported offending. On the basis of social-cognitive theory (Bandura, 1991), we believe that the direction of influence will flow more strongly from attitudes (moral disengagement) to behavior (offending), than in the reverse direction. Still, the reciprocal path is important to consider. Engaging in misconduct may lead one to devalue moral standards (Hirschi, 1969), which would be evidenced by offending predicting change in moral disengagement. We test both the main hypothesized effect and the reciprocal effect by allowing change from one wave to the next in each variable to be influenced by the prior level of the other variable.

In LCS models, change in a given variable from one time point to the next-the latent change score-is not directly calculated. Rather, it is modeled as difference that accumulates between latent true scores for adjacent time points. (The latent true scores are the components of the measured scores that are not a product of measurement error.) This approach has the advantage of allowing for the direct estimation of the degree to which levels of one variable prospectively predict change over time in another variable. In our case, it allows us to directly test whether level of moral disengagement at a given time point is related to change in of fending between that time point and the next (and vice versa). These estimates are made while accounting for concurrent associations and other potential sources of correlation between the key variables, such as similar but independent natural patterns of change over time. Though these models are correlational and therefore cannot determine causation, they are an improvement over other analytic approaches (e.g., cross lag models) in that they allow for direct modeling of the outcomes of interest - the change in offending and moral disengagement from one time point to the next. It is also important to note that the LCS model is fundamentally different from the latent growth curve model, in that the former is a dynamic system approach: The rate of change in a given variable is defined at each occasion, based on predictors in the model, including its prior state and a constant slope representing its growth (McArdle \& Hamagami, 2001). Thus, the estimated latent change in a given variable will vary across different time points. In contrast, the latent growth curve model is a static approach; the rate of change is assumed to be time-invariant.

In a bivariate LCS model involving repeated measures of two variables $(X$ and $Y$ ), the latent change scores $(\Delta x$ and $\Delta y)$ are allowed to be influenced by three factors: $\Delta y$ is predicted by (a) the level of the true score for $Y(y)$ at the start of the interval (the proportional effect); (b) a constant growth factor (slope) for $y$; and (c) (true) the level of the other variable, $x$, at the start of the interval (the coupling effect). These predictors of change in $y$ allow for the estimated trajectory of $y$ to be nonlinear. Correspondingly, $\Delta x$ is estimated to be influenced by the prior level of $x$, the slope for $x$, and the prior level of $y$. These effects are estimated while controlling for correlations between concurrent measures of $X$ and $Y$ (pairings), as well as correlations between the initial levels and slopes for $x$ and $y$. Thus, the coupling effects represent conservative estimates of the effect of each variable on change over time in the other. These coupling effects - the effect of moral disengagement (at time $t$ ) on change in self-reported offending (between $t$ and $t+6$ months), $\gamma_{\mathrm{SRO}}$, and the effect of self-reported offending (at time $t$ ) on change in moral disengagement (between $t$ and $t+$ 6 months), $\gamma_{\mathrm{MD}}$ - are the key parameters of interest in our bivariate LCS model. If the coupling effect of moral disengagement on change in self-reported offending is significant, it suggests that moral disengagement is a leading indicator of change in offending. As the coupling effect is estimated after accounting for incidental correlations in the way both variables tend to change over time, a significant estimate is suggestive of a causal effect of one variable on the other.

In addition, we test whether callousness acts as a confound on the relation between moral disengagement and self-reported offending. This is accomplished by adding the repeated measures of callousness (modeled as a latent growth curve) to the LCS model of moral disengagement and offending. We regress levels of moral disengagement and offending on concurrent measures of callousness and reexamine the strength of the longitudinal effects of moral disengagement and offending on one another. Reduction in these coefficients, compared to the model excluding callousness, would signal confounding. 
Finally, we examine whether official records of offending are related to moral disengagement. Given that official records provide a relatively insensitive measure of offending - the vast majority of legal infractions go undetected (Brame, Fagan, Piquero, Schubert, \& Steinberg, 2004; Dunford \& Elliott, 1984)—we do not expect moral disengagement to be as strongly related to official records as to self-reported offending. Still, it is important to examine whether such a relationship exists because of the concern that the observed association between moral disengagement and self-reported offending might be an artifact of shared method variance. A bivariate latent growth model is used to test whether moral disengagement is statistically related to official records of offending.

All of the models are estimated in a structural equation modeling framework using Mplus (Version 5.21). The models including self-reported offending are estimated with maximum-likelihood estimation. Those that include official record of offending are estimated with a robust weighted least squares estimator, which is recommended for use with dichotomous dependent variables (Muthén \& Muthén, 2009). Because we expect both self-report and official record of offending to be influenced by one's history of antisocial behavior and by the proportion of time one has been "on the streets" (i.e., not residing in secure facilities; see Piquero et al., 2001), we account for both of these factors in our analyses. We initially considered age as a covariate as well but excluded it in the final analysis, as it bore no relation to trajectories of moral disengagement.

\section{Method}

\section{Participants}

Participants were adolescents enrolled in the Pathways to Desistance study, a prospective study of 1,354 serious juvenile offenders ( $86 \%$ male) in Phoenix $(N=654)$ and Philadelphia $(N=$ 700). Complete details of the study methodology and its rationale are provided in Schubert et al. (2004) and Mulvey et al. (2004), respectively. As the number of female offenders was too small to provide enough power for the longitudinal multivariate models, we analyzed only the male offenders $(N=1,169)$ for the present study (excluding the one male participant who was 19 years old at the initial interview).

Adolescents were eligible for the study if they were $14-17$ years of age (mean 16.55) at the time of their adjudication and if their crimes included felony offenses (against persons and property), certain misdemeanor weapons offenses, or sexual assault. Because drug law violations represent an especially large proportion of the offenses committed by this age group, the proportion of male juveniles with drug offenses was capped at $15 \%$ of the sample at each site to ensure adequate sample heterogeneity with respect to criminal offending. Participants were interviewed, on average, 36.9 days $(S D=20.6)$ after their adjudication (for those in the juvenile system) or their decertification hearing in Philadelphia or an adult arraignment in Phoenix (if in the adult system). Participants were mostly of lower socioeconomic status (less than $8 \%$ of the participants had at least one parent with a 4-year college degree, and 31.6\% did not have a parent with a high-school diploma). The racial/ethnic composition was $42.1 \%$ African American, 34.0\% Hispanic American, $19.2 \%$ non-Hispanic Caucasian, and $4.6 \%$ other.

\section{Procedure}

The juvenile court in each locale provided the names of eligible adolescents (based on age and adjudicated charge). Interviewers then obtained consent from the participant and a guardian. Interviews were conducted at a facility (if the juvenile was confined), the juvenile's home, or a mutually agreed-upon location in the community. All recruitment and assessment procedures were approved by the institutional review boards of the participating universities. Adolescents were paid between $\$ 50$ and $\$ 150$ per interview (payments increased at each time point) for their participation, except when facility rules prohibited doing so.

The baseline interview was administered over 2 days in two 2-hr sessions. Interviewers and participants sat side by side facing a computer, and questions were read aloud to avoid any problems caused by reading difficulties. Respondents could answer the questions aloud or, to maximize privacy, enter their responses on a keypad (although in some facilities, this option was not available). Attempts were made to conduct interviews out of the earshot of other individuals. Honest reporting was encouraged by informing participants of the requirement for confidentiality placed upon us by the U.S. Department of Justice, which prohibits disclosure of personally identifiable information except in cases of imminent danger.

Of those approached, $80 \%$ agreed to participate. Participants were interviewed every 6 months for 36 months. The percentages of completed interviews among enrolled participants were $93 \%$ at 6 months, $93 \%$ at 12 months, $91 \%$ at 18 months, $91 \%$ at 24 months, $91 \%$ at 30 months, and $91 \%$ at 36 months. Thus, there was very low attrition of the sample over time.

\section{Measures}

Moral disengagement. Moral disengagement was assessed at each time point using the Mechanisms of Moral Disengagement scale (Bandura et al., 1996). The scale consists of 32 statements justifying acts of wrongdoing, such as, "Kids who get mistreated usually do things that deserve it," "Stealing some money is not too serious compared to those who steal a lot of money," and "To hit obnoxious classmates is just giving them a lesson." Participants responded to each statement on a 3-point scale ranging from disagree to agree, with higher scores indicating greater moral disengagement. The measure had acceptable internal consistency ( $\alpha=.88$ at baseline). As in other research on moral disengagement (Pelton et al., 2004), the items loaded as a single factor in a principle components analysis and were averaged to compute scale scores. In the structural equation models that follow, moral disengagement scores were multiplied by 10 for ease of interpretation. (This type of scaling adjustment has no impact on the relations among variables.)

Callousness. Callousness was assessed at each follow-up interview using the Callous Unemotional dimension of the Youth Psychopathic Traits Inventory (YPI; Andershed, Kerr, Stattin, \& Levander, 2002), a self-report measure developed to detect psychopathy among youths ( $\alpha=.71$ at the first follow-up interview). While the YPI is not the measure most commonly used to specifically assess callousness, it has several strengths: (a) It was developed for use with adolescents; (b) the items do not frame callousunemotional traits as deficits (e.g., "My emotions are more shallow 
than others"') but instead as characteristics that should seem neutral or even appealing to those with psychopathic traits (e.g., "I usually feel calm when other people are scared"); and (c) it is free of items that assess antisocial behavior (Andershed et al., 2002). The Callous Unemotional scale is composed of 15 items tapping remorselessness (e.g., "I seldom regret things I do, even if other people feel that they are wrong"), unemotionality (e.g., "I don't let my feelings affect me as much as other people's feelings seem to affect them"), and callousness (e.g., "It's important to me not to hurt other people's feelings" [reverse coded]). Youths respond on a 4-point scale ranging from does not apply at all to applies very well. Scores are calculated as the sum of responses with higher scores indicating greater emotional deficit. The Callous Unemotional dimension of the YPI is significantly associated with the conceptually equivalent affective scale of the Psychopathy Checklist - Youth Version (Skeem \& Cauffman, 2003) and yields low to moderate correlations with a variety of self-report conduct problem indices, supporting its convergent validity (Cauffman, Kimonis, Dmitrieva, \& Monahan, 2009).

Self-reported offending. At the baseline interview and each subsequent time point, an adapted version of the Self-Report of Offending scale (Huizinga, Esbensen, \& Weiher, 1991) was used to assess antisocial behavior. Youths reported whether they had been involved in 22 types of antisocial and illegal activities (e.g., "Taken something from another person by force, using a weapon?"; "Used checks or credit cards illegally?"; "Ever driven while intoxicated?") during the 6 months prior to the interview. Antisocial behavior was calculated as the percentage of items a youth endorsed, with higher scores indicating more antisocial behavior. Previous research based on this sample has established the reliability of this adapted version of the Self-Report of Offending scale (Knight, Little, Losoya, \& Mulvey, 2004). To reduce the skewness in the measures of antisocial behavior, these variables were $\log$ transformed.

Lifetime offending. Lifetime offending was assessed using the same measure of self-reported offending but was based on youths' baseline reports of whether they had ever been involved in the activities described. Lifetime offending was calculated as the proportion of items a youth endorsed. This variable was used as a control.

Official record of offending. Participants' court files were searched to obtain official records of offending. The data consist of the number of arrests resulting in a court referral within the 6 months preceding each interview. For the baseline interview, the count does not include the arrest referral for the current incident. Because multiple arrests in a given 6-month period were relatively rare (rates never reach 5\% after baseline), the data were dichotomized (any arrests vs. no arrests) for the present analyses.

Opportunity to offend. Many of the participants were limited in their ability to commit the types of offenses included in the measure of antisocial behavior, due to confinement in a secure facility (including correctional, psychiatric, drug and alcohol treatment, and residential treatment facilities). To account for dynamic change in the opportunity to offend due to participants' movement in and out of secure settings (Piquero et al., 2001), we used the proportion of days not spent confined (i.e., time spent on the streets) since the previous interview as a time-varying covariate of offending in our analyses. These proportions were ascertained from a life calendar completed at each interview.

\section{Missing Data}

Coverage-full responses-ranged from $84 \%$ to $100 \%$ for all covariances among the study variables except for those including the 6-month assessment of callousness, which ranged from $73 \%$ to $79 \%$ because this measure was added after the study began. No variable had more than $10 \%$ missing data, except for the 6-month assessment of callousness, which was missing for $21 \%$ of participants. However, because the elevated rate of missing data on this assessment was due to study procedures, it was considered to be missing completely at random. Otherwise, missing data were assumed to be missing at random. ${ }^{2}$

\section{Results}

\section{Descriptive Statistics}

Descriptive statistics for all repeatedly measured variables (in their raw forms) are shown in Table 1. Concurrent measures of moral disengagement and callousness were, as expected, moderately to strongly correlated, ranging from .43 to .48 and averaging .45. Stability, as measured by intraclass correlation, across the 3 -year follow-up period (6 months to 36 months) was moderate for both moral disengagement, $0.42,95 \%$ CI [0.37, 0.47)], and callousness, $0.40,95 \%$ CI $[0.34,0.46)]$. Partial correlations of moral disengagement and callousness with self-report and official record of offending (controlling for the effects of opportunity to offend) are shown in Table 2, as is the correlation between self-report and official record of offending. These reveal consistent, moderate correlations of moral disengagement and callousness with selfreported offending but only weak, though sometimes significant, relations between these variables and official record of offending. While not strong, the significant partial correlations (controlling for opportunity to offend) between self-report and official record of offending at each follow-up point ( $r_{\mathrm{p}} \mathrm{s}$ range from .19 to .26) suggests that youths' self-report of offending is corroborated by official court record.

\section{Longitudinal Relations Between Moral Disengagement and Self-Reported Offending}

Figure 1 shows a path diagram of the bivariate LCS model used to analyze the longitudinal relations between moral disengagement and self-reported offending. In the figure, SRO represents selfreported offending, MD represents moral disengagement and Opp represents opportunity to offend. Observed variables are represented with squares and latent variables with circles. Singleheaded arrows signify regression paths and double-headed arrows represent covariance $(\sigma)$ or, if both ends point to the same variable, variance. The letter $e$ indicates an error term. Parameters with the same name are constrained to be equal. Paths marked with 1 are set to 1 . All variables are centered either on their mean or, in the case of repeatedly measured variables, on their grand mean. Means are

\footnotetext{
${ }^{2}$ We tested whether participants who missed the 36-month interview $(N=112)$ differed from those who completed it in terms of their baseline levels of moral disengagement, self-reported offending, and lifetime offending or their 6-month levels of callousness. No significant differences were found. These results will be provided by the authors upon request.
} 
Table 1

Means and Standard Deviations for All Variables and Stability for Repeatedly Measured Variables

\begin{tabular}{|c|c|c|c|c|c|c|c|c|c|c|}
\hline \multirow[b]{2}{*}{ Time point } & \multicolumn{2}{|c|}{$\begin{array}{c}\text { Moral } \\
\text { disengagement } \\
\text { (range: } 1-3 \text { ) }\end{array}$} & \multicolumn{2}{|c|}{$\begin{array}{l}\text { Callousness } \\
\text { (range: 15-60) }\end{array}$} & \multicolumn{2}{|c|}{$\begin{array}{l}\text { Self-reported } \\
\text { offending }(\%)\end{array}$} & \multicolumn{2}{|c|}{$\begin{array}{c}\text { Opportunity to } \\
\text { offend } \\
\text { (prop. of time) }\end{array}$} & \multicolumn{2}{|c|}{$\begin{array}{l}\text { Official record of } \\
\text { offending } \\
\text { (prop. arrested) }\end{array}$} \\
\hline & $M$ & $S D$ & $M$ & $S D$ & $M$ & $S D$ & $M$ & $S D$ & $M$ & $S D$ \\
\hline Baseline & 1.63 & $(0.35)$ & & & 15.53 & (15.67) & 0.52 & $(0.41)$ & 0.89 & $(0.31)$ \\
\hline 6 mo. & 1.59 & $(0.37)$ & 33.77 & $(6.81)$ & 9.07 & (12.84) & 0.55 & $(0.42)$ & 0.16 & $(0.37)$ \\
\hline $12 \mathrm{mo}$. & 1.55 & $(0.36)$ & 33.07 & (6.46) & 8.01 & (12.26) & 0.65 & $(0.41)$ & 0.17 & $(0.38)$ \\
\hline $18 \mathrm{mo}$. & 1.52 & $(0.38)$ & 32.74 & (6.70) & 7.13 & (10.99) & 0.66 & $(0.41)$ & 0.19 & $(0.40)$ \\
\hline 24 mo. & 1.51 & $(0.37)$ & 33.08 & (6.57) & 6.74 & (11.45) & 0.68 & $(0.41)$ & 0.22 & $(0.42)$ \\
\hline $30 \mathrm{mo}$. & 1.49 & $(0.36)$ & 32.25 & (6.63) & 5.28 & $(9.95)$ & 0.52 & $(0.41)$ & 0.19 & $(0.40)$ \\
\hline $36 \mathrm{mo}$. & 1.48 & $(0.36)$ & 32.53 & (6.59) & 5.39 & $(10.28)$ & 0.55 & $(0.42)$ & 0.19 & (0.39) \\
\hline Stability & 0.55 & & 0.49 & & 0.39 & & 0.46 & & 0.08 & \\
\hline
\end{tabular}

Note. The stability coefficient is the average Pearson correlation across all assessments. Prop. = proportion.

estimated for all observed control variables and latent growth parameters.

Latent change in the key variables (moral disengagement and self-reported offending) is modeled as arising from three sources: a proportional effect $(\beta)$, constant growth (all $\alpha \mathrm{s}=1$ ) emanating from a latent slope $\left(\mathrm{MD}_{\mathrm{s}}\right.$ or $\left.\mathrm{SRO}_{\mathrm{s}}\right)$, and a coupling effect $(\gamma)$. Modeling both a proportional and a linear growth effect allows the pattern of change in each variable to be curvilinear (see Figure 2). The coupling effects are most important for testing the hypothesis that moral disengagement affects self-reported offending: $\gamma_{\text {SRO }}$ represents the effect of moral disengagement on change in self-reported offending. The model simultaneously estimates the reciprocal effect $\left(\gamma_{\mathrm{MD}}\right)$ of self-reported offending on change in moral disengagement. In addition, a latent intercept is estimated for moral disengagement $\left(\mathrm{MD}_{0}\right)$ and self-reported offending $\left(\mathrm{SRO}_{0}\right)$. Covariance between the residuals of moral disengagement and offending at each time point (the pairing of these variables) is also estimated $\left(\sigma_{\text {SRO,MD }}\right)$. The coupling, pairing, proportional effect, and intercept parameters are held constant over time, resulting in a very parsimonious model.

The basic bivariate LCS model includes only 21 freely estimated parameters. However, the present model also accounts for the covariate effects of (a) lifetime offending on the growth parameters and (b) opportunity to offend on self-reported offending at each follow-up point. This requires the addition of 24 estimated parameters and results in well-fitting model, $\chi^{2}(207)=632.69, p<.001 ;$ CFI $=.94 ;$ RMSEA $=.042$ (.038-.046).

The results of this analysis (displayed in Table 3 ) suggest that moral disengagement influences change in self-reported offending and, conversely, self-reported offending influences change in moral disengagement. When these estimates are standardized (using the model-estimated variance for each observed outcome) it becomes clear that the effect of moral disengagement on change in self-reported offending (standardized $\gamma_{\text {SRO }}=$ $1.14, p<.001)$ is about $70 \%$ stronger than the reciprocal effect (standardized $\gamma_{\mathrm{MD}}=-0.67, p<.05$ ). Thus, the influence of moral disengagement on offending appears to be greater than that of offending on moral disengagement. Because the effects are on change scores, the positive coefficient for $\gamma_{\mathrm{SRO}}$ suggests that as levels of moral disengagement increase, the change score for offending increases. In other words, higher levels of moral disengagement are associated with increasing levels of offending, whereas lower levels of moral disengagement are associated with declining levels of offending. The negative estimate for $\gamma_{\mathrm{MD}}$ indicates that higher earlier levels of offending at a given point are associated with subsequent decreases in moral disengagement $-\mathrm{a}$ somewhat counterintuitive finding that we discuss later.

Bear in mind that these estimates are made after accounting for other effects in the model, such as the patterns of growth in moral disengagement and offending, both of which had negative slopes, and the covariance between concurrent measures of

Table 2

Concurrent Partial Correlations With Self-Reported Offending and Official Record of Offending, Controlling for Opportunity to Offend

\begin{tabular}{|c|c|c|c|c|c|c|}
\hline Partial correlation & 6 month & 12 month & 18 month & 24 month & 30 month & 36 month \\
\hline \multicolumn{7}{|l|}{ With self-reported offending } \\
\hline Moral disengagement & $.33^{* * * *}$ & $.30^{* * * *}$ & $.34^{* * * * * *}$ & $.30^{* * * * *}$ & $.33^{* * * * * *}$ & $.29^{* * * *}$ \\
\hline Callousness & $.27^{* * * *}$ & $.31^{* * * *}$ & $.30^{* * * * *}$ & $.30^{* * * * *}$ & $.24^{* * * *}$ & $.24^{* * * *}$ \\
\hline Official record of offending & $.19^{* * * *}$ & $.25^{* * * *}$ & $.26^{* * * * *}$ & $.22^{* * * * *}$ & $.22^{* * * * *}$ & $.25^{* * * *}$ \\
\hline \multicolumn{7}{|l|}{ With official record of offending } \\
\hline Moral disengagement & .02 & .04 & $.09^{* *}$ & .02 & $.12^{* * * * *}$ & $.07^{*}$ \\
\hline Callousness & -.01 & .03 & $.07^{*}$ & $.08^{*}$ & $.08^{*}$ & $.09^{\text {*** }}$ \\
\hline
\end{tabular}

${ }^{*} p<.05 . \quad * * p<.01 . \quad * * * 0<.001$. 


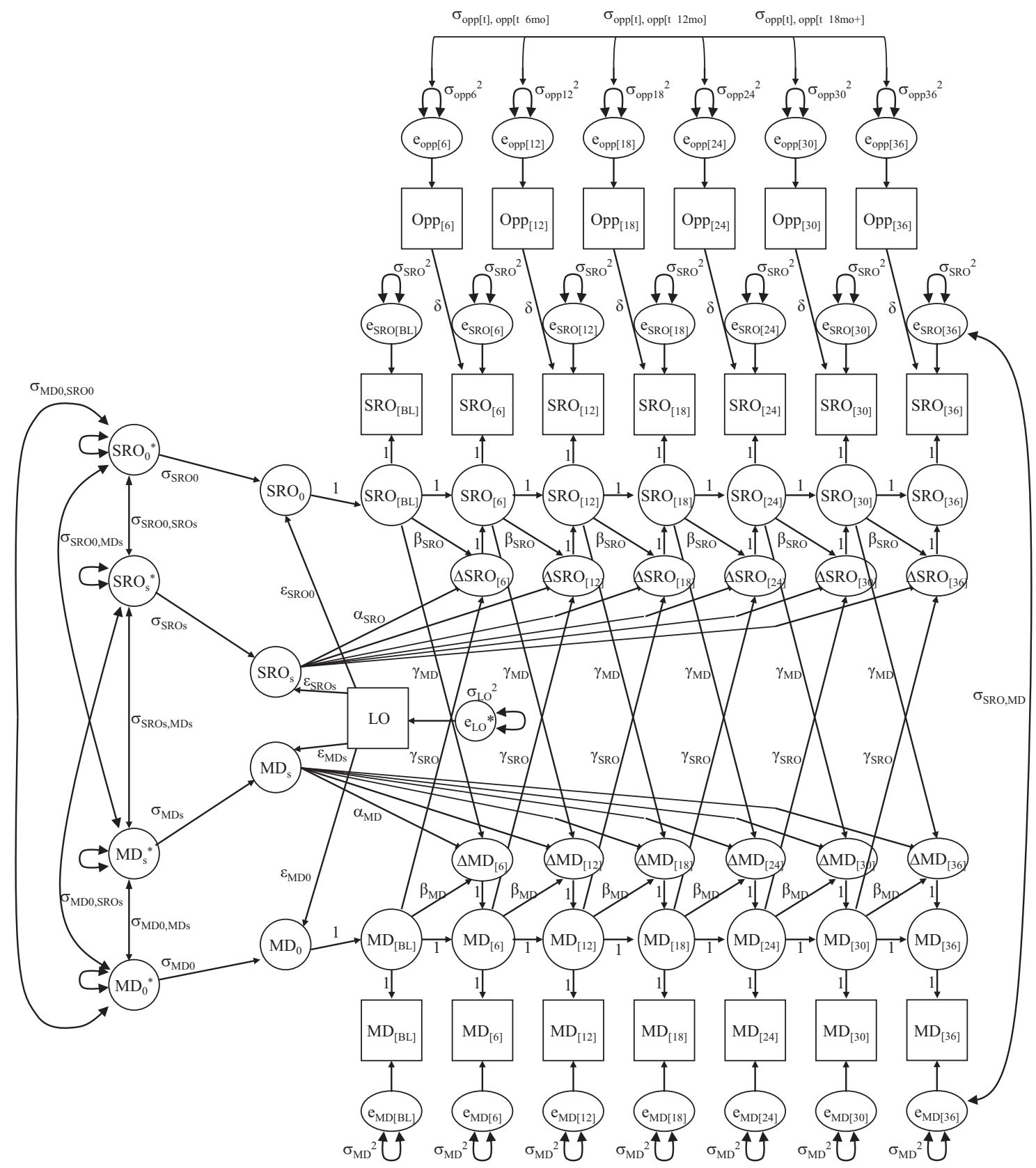

Figure 1. Bivariate latent change score model of moral disengagement (MD) and self-reported offending (SRO), controlling lifetime offending (LO) and opportunity to offend (Opp). Not illustrated is a single covariance estimate for lifetime offending with each measure of opportunity to offend. Though shown only once, the pairing of MD and SRO $\left(\sigma_{\mathrm{SRO}, \mathrm{MD}}\right)$ is estimated based on the covariance at each time point. Observed variables are represented with squares and latent variables with circles. Single-headed arrows signify regression paths and double-headed arrows represent covariance $(\sigma)$ or, if both ends point to the same variable, variance. The letter $e$ indicates an error term. Parameters with the same name are constrained to be equal. Paths marked with 1 are set to 1 . All variables are centered on either their mean or, in the case of repeatedly measured variables, their grand mean. Means are estimated for all observed control variables and latent growth parameters.

moral disengagement and offending $\left(\sigma_{\mathrm{SRO}, \mathrm{MD}}\right)$, which was positive $(r=.32, p<.001)$. The average trajectories for both moral disengagement and offending declined in a curvilinear fashion (see Figure 2). As expected, the intercepts of these variables were positively associated with lifetime offending.

\section{Testing Whether Callousness Is a Confound}

To ensure that the observed relations between moral disengagement and offending were not a result of callousness giving rise to both, the model was reestimated with callousness partialled. To 

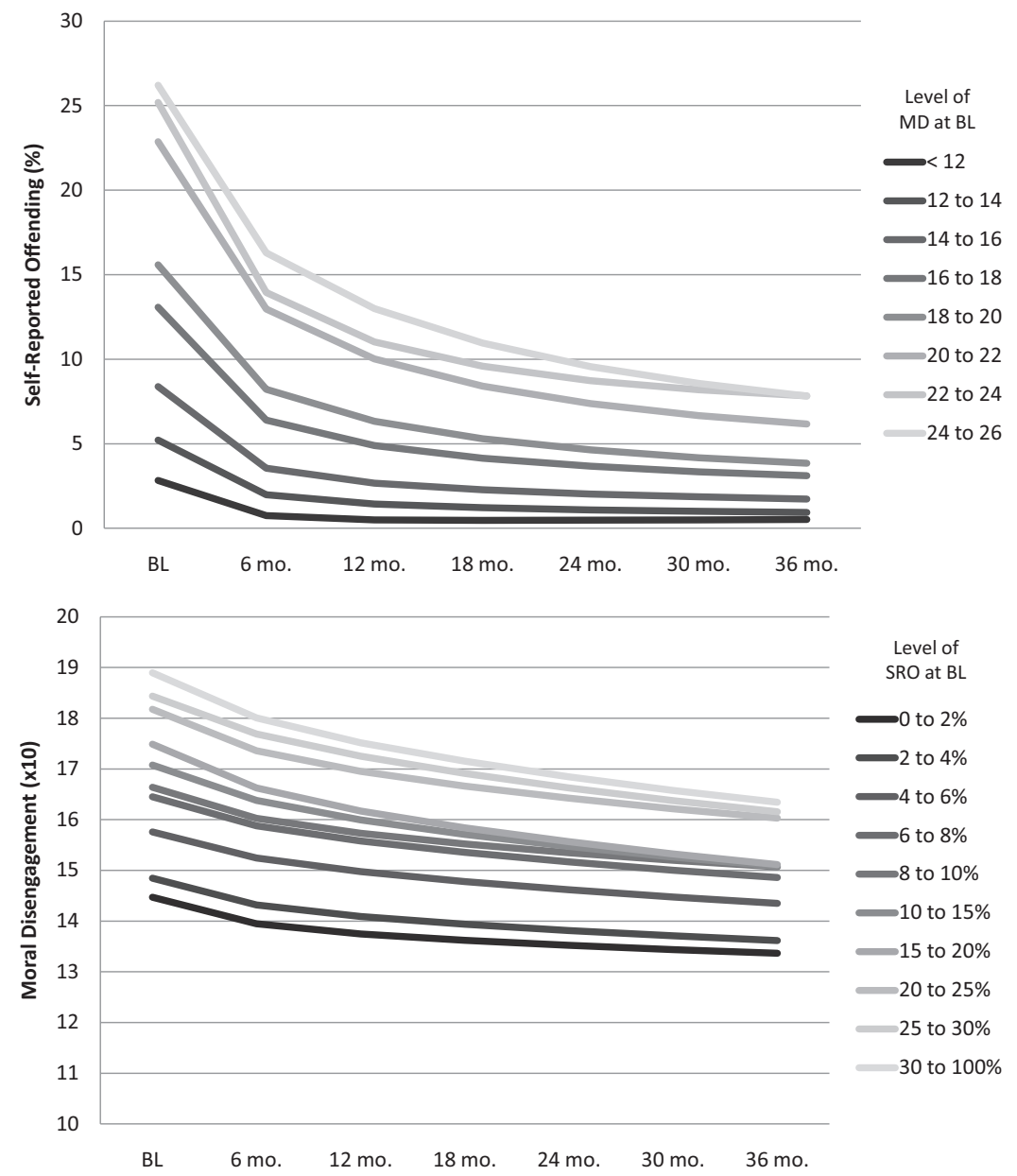

Figure 2. Estimated trajectories of self-reported offending (SRO; upper panel) and moral disengagement (MD; lower panel) for individuals with different initial levels of the other variable. $\mathrm{BL}=$ baseline time point.

account for the effects of callousness on both self-reported offending and moral disengagement, we added the repeated measures of callousness, specified as evincing linear growth, to the model. Paths were added to the model regressing the observed moral disengagement and offending variables on the observed callousness variables, with these estimates held constant over time. In addition, the latent intercept and slope terms for callousness were allowed to covary with the growth parameters for moral disengagement and self-reported offending, as well as with lifetime offending. (See Figure 3 for a simplified illustration of this model and its results.) Thus, 18 new, freely estimated parameters were added to the model, which had good fit, $\chi^{2}(342)=817.04, p<$ $.001 ; \mathrm{CFI}=.95 ; \mathrm{RMSEA}=.034$ (.031-.038). The growth parameter estimates for callousness, reported in Table 3, show that, on average, callousness tended to decline over time after accounting for correlations between its growth parameters and those of moral disengagement and self-reported offending.

As predicted, the repeated measures of callousness were significantly related to the repeated measures of both moral disengagement (standardized estimate $=.20, p<.001$ ) and offending (standardized estimate $=.06, p<.001)$. However, the longitudinal associations between moral disengagement and offending were not substantively attenuated in this model compared to the prior model excluding callousness. The estimated influence of moral disengagement on change in self-reported offending was nearly identical to the prior model, as was the estimated effect of self-reported offending on change in moral disengagement (see Table 3 and Figure 3).

To statistically test whether either coupling effect, $\gamma_{\mathrm{SRO}}$ or $\gamma_{\mathrm{MD}}$, had changed significantly as a result of adding callousness to the model, we set each path (one at a time) equal to its weight in the previous model that did not include callousness. If the path had changed significantly from the previous model, doing this would cause a significant increase in the chi-square. The results showed that neither path's weight changed significantly as a result of adding callousness to the model: $\Delta \chi^{2}(1)$ for $\gamma_{\mathrm{SRO}}=0.08, p=n s$; $\Delta \chi^{2}(1)$ for $\left.\gamma_{\mathrm{MD}}=0.27, p=n s\right)$. A similar test of the residual correlation for concurrent measures of moral disengagement and self-reported offending $\left(\sigma_{\mathrm{SRO}, \mathrm{MD}}\right)$ indicated that this parameter was also not significantly reduced compared to the previous model, $\Delta \chi^{2}(1)$ for $\sigma_{\mathrm{SRO}, \mathrm{MD}}=0.56, p=n s$. Thus, it does not appear that callousness acts as a confound on the longitudinal or concurrent associations between moral disengagement and offending. 
Table 3

Results of Latent Difference Score Models Examining Longitudinal Effects of Moral Disengagement (MD) and Self-Reported Offending (SRO) on One Another

\begin{tabular}{|c|c|c|c|c|c|c|c|}
\hline \multirow[b]{2}{*}{ Model parameters } & \multirow[b]{2}{*}{ Sym } & \multicolumn{3}{|c|}{ Model without callousness } & \multicolumn{3}{|c|}{ Model with callousness } \\
\hline & & $B$ & CI lower & CI upper & $B$ & CI lower & CI upper \\
\hline \multicolumn{8}{|l|}{ Effects on change estimates (coupling) } \\
\hline$\Delta \mathrm{SRO}$ on latent $\mathrm{MD}$ & $\gamma_{\mathrm{SRO}}$ & $0.486^{* *}$ & 0.125 & 0.847 & $0.445^{* *}$ & 0.180 & 0.710 \\
\hline$\Delta \mathrm{MD}$ on latent $\mathrm{SRO}$ & $\gamma_{\mathrm{MD}}$ & $-0.691^{*}$ & -1.335 & -0.046 & $-0.561^{*}$ & -1.009 & -0.114 \\
\hline \multicolumn{8}{|l|}{ Autoproportion effects } \\
\hline$\Delta$ SRO on latent SRO & $\beta_{\mathrm{SRO}}$ & $-1.118^{* * * *}$ & -1.589 & -0.648 & $-1.054^{* * *}$ & -1.388 & -0.720 \\
\hline$\Delta \mathrm{MD}$ on latent $\mathrm{MD}$ & $\beta_{\mathrm{MD}}$ & 0.216 & -0.184 & 0.615 & 0.129 & -0.165 & 0.423 \\
\hline \multicolumn{8}{|l|}{ Growth parameters (intercepts) } \\
\hline SRO intercept & $\mu_{\mathrm{SROO}}$ & $0.853^{\text {****** }}$ & 0.794 & 0.913 & $0.857^{* * * *}$ & 0.799 & 0.915 \\
\hline SRO slope & $\mu_{\mathrm{SROS}}$ & $-0.150^{* * * *}$ & -0.233 & -0.066 & $-0.151^{* * *}$ & -0.223 & -0.078 \\
\hline MD intercept & $\mu_{\mathrm{MDO}}$ & $0.931^{* * * *}$ & 0.738 & 1.125 & $0.879^{* * *}$ & 0.697 & 1.062 \\
\hline MD slope & $\mu_{\mathrm{MDs}}$ & $-0.248^{* * * *}$ & -0.306 & -0.190 & $-0.240^{* * *}$ & -0.284 & -0.195 \\
\hline CU intercept & & & & & $0.828^{* * * *}$ & 0.430 & 1.226 \\
\hline CU slope & & & & & $-0.236^{* * * *}$ & -0.316 & -0.155 \\
\hline \multicolumn{8}{|l|}{ Growth parameters (variance) } \\
\hline SRO intercept & $\mathrm{SRO}_{0}^{*}$ & 0.061 & -0.029 & 0.151 & 0.062 & -0.027 & 0.151 \\
\hline SRO slope & $\mathrm{SRO}_{\mathrm{s}}^{*}$ & 1.338 & -0.467 & 3.143 & 1.073 & -0.024 & 2.169 \\
\hline MD intercept & $\mathrm{MD}_{0}^{*}$ & $6.031^{* * * * *}$ & 5.187 & 6.875 & 5.529 & 4.755 & 6.303 \\
\hline MD slope & $\mathrm{MD}_{\mathrm{s}}^{*}$ & 0.401 & -0.481 & 1.282 & 0.245 & -0.129 & 0.619 \\
\hline CU intercept & & & & & $25.623^{* * * *}$ & 21.687 & 29.560 \\
\hline CU slope & & & & & $0.503^{* * * *}$ & 0.339 & 0.667 \\
\hline \multicolumn{8}{|l|}{ Covariance parameters } \\
\hline SRO(t) with MD(t) (Pairing) & $\sigma_{\mathrm{SRO}, \mathrm{MD}}$ & $0.224^{* * *}$ & 0.158 & 0.291 & $0.200^{* * * *}$ & 0.138 & 0.262 \\
\hline SRO intercept, slope & $\sigma_{\text {SROO,SROs }}$ & $0.119^{*}$ & 0.023 & 0.215 & $0.113^{* *}$ & 0.037 & 0.189 \\
\hline MD intercept, slope & $\sigma_{\mathrm{MDO}, \mathrm{MDs}}$ & -1.111 & -3.088 & 0.867 & -0.671 & -1.961 & 0.620 \\
\hline SRO intercept, MD intercept & $\sigma_{\mathrm{MDO}, \mathrm{SROO}}$ & 0.034 & -0.140 & 0.207 & 0.050 & -0.111 & 0.212 \\
\hline SRO slope, MD slope & $\sigma_{\mathrm{SROs}, \mathrm{MDs}}$ & 0.655 & -0.738 & 2.048 & 0.408 & -0.361 & 1.178 \\
\hline SRO intercept, MD slope & $\sigma_{\mathrm{SROO}, \mathrm{MDs}}$ & 0.071 & -0.011 & 0.152 & 0.055 & -0.002 & 0.112 \\
\hline SRO slope, MD intercept & $\sigma_{\mathrm{MDO}, \mathrm{SRO}}$ & $-2.341^{*}$ & -4.273 & -0.408 & $-1.929^{* * *}$ & -3.186 & -0.671 \\
\hline CU intercept, slope & & & & & $-1.499^{* * * *}$ & -2.189 & -0.809 \\
\hline CU intercept, SRO intercept & & & & & 0.202 & -0.184 & 0.587 \\
\hline CU intercept, SRO slope & & & & & $-0.960^{*}$ & -1.901 & -0.019 \\
\hline $\mathrm{CU}$ intercept, MD intercept & & & & & $4.246^{* * *}$ & 3.112 & 5.380 \\
\hline CU intercept, MD slope & & & & & -0.229 & -1.089 & 0.632 \\
\hline CU slope, SRO intercept & & & & & 0.034 & -0.047 & 0.115 \\
\hline CU slope, SRO slope & & & & & -0.024 & -0.121 & 0.073 \\
\hline CU slope, MD intercept & & & & & -0.042 & -0.273 & 0.189 \\
\hline CU slope, MD slope & & & & & 0.053 & -0.014 & 0.120 \\
\hline Opportunity, SRO intercept & & 0.009 & -0.011 & 0.028 & 0.008 & -0.011 & 0.027 \\
\hline \multicolumn{8}{|l|}{ Effects of control variables } \\
\hline SRO intercept on Lifetime Offending & $\varepsilon_{\text {SROO }}$ & $3.528^{* * * *}$ & 3.259 & 3.797 & $3.552^{* * * *}$ & 3.283 & 3.821 \\
\hline SRO slope on Lifetime Offending & $\varepsilon_{\text {SROs }}$ & 0.108 & -0.614 & 0.829 & 0.375 & -0.092 & 0.841 \\
\hline MD intercept on Lifetime Offending & $\varepsilon_{\mathrm{MDs}}$ & $6.208^{* * * *}$ & 5.430 & 6.986 & $5.554^{* * * *}$ & 4.797 & 6.311 \\
\hline MD slope on Lifetime Offending & $\varepsilon_{\mathrm{MD} 0}$ & 0.252 & -0.274 & 0.777 & $0.363^{*}$ & 0.013 & 0.712 \\
\hline $\mathrm{SRO}(\mathrm{t})$ on Opportunity & $\delta$ & $0.278^{* * * *}$ & 0.197 & 0.358 & $0.272^{* * * *}$ & 0.194 & 0.350 \\
\hline $\mathrm{SRO}(\mathrm{t})$ on $\mathrm{CU}(\mathrm{t})$ & & & & & $0.013^{* * *}$ & 0.007 & 0.019 \\
\hline $\mathrm{MD}(\mathrm{t})$ on $\mathrm{CU}(\mathrm{t})$ & & & & & $0.108^{* * * * *}$ & 0.095 & 0.121 \\
\hline
\end{tabular}

Note. "Sym" = the symbol for the parameter as labeled in Figure 1; CU = callous-unemotional traits; SRO = self-reported offending; MD = moral disengagement. The shorthand "Y on X" signifies a regression path and "Y, $\mathrm{X}$ " signifies covariance. In the interest of space, means and variances for repeated measures are omitted.

${ }^{*} p<.05 .{ }^{* * *} p<.01$. $^{* * * *} p<.001$.

\section{Moral Disengagement and Official Record of Offending}

To confirm that the relations between moral disengagement and offending were not due merely to shared method variance, we estimated an additional model investigating the relations between moral disengagement and official record of offending (coded as a dichotomous variable) for the six follow-up time points. ${ }^{3}$ A bivariate LCS

\footnotetext{
${ }^{3}$ The baseline interview was excluded because, while we had official records for the 6 months preceding baseline, we had no ability to account for opportunity to offend during this period. This is a bigger problem when modeling official record offending than when modeling self-reported offending, which is less dependent on confinement.
} 


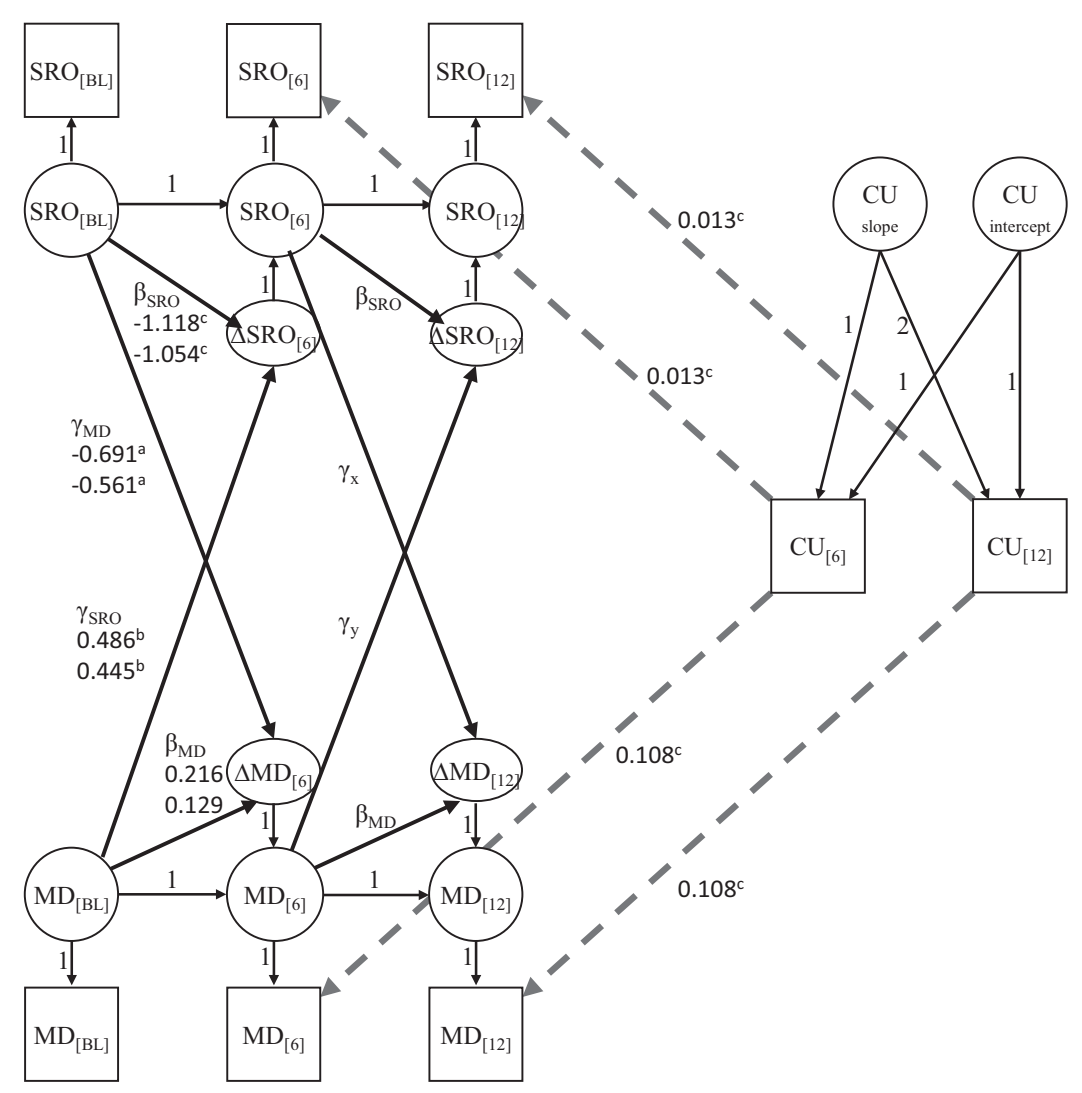

Figure 3. Simplified version of the latent change score model including callousness (CU) as a potential confound. The model is only displayed out to the third time point (12 months); the nondisplayed parts of the model are redundant. Unstandardized estimates are shown. Where two estimates are shown, the top one refers to the model without callousness and the bottom one refers to the model including callousness. Paths with the same name are constrained to be equal. ${ }^{\mathrm{a}} p<.05 .{ }^{\mathrm{b}} p<.01 .{ }^{\mathrm{c}} p<.001$.

model could not be used because it would not converge. Instead, growth models were estimated for both variables and relations among them examined. On the basis of pretesting of no-growth, linear, and quadratic growth models-specifically, by comparing the Bayesian information criterion fit statistics for each modelquadratic growth was specified for both variables. For official offending, the quadratic term was fixed (i.e., the variance was set equal to zero), because its variance was nonsignificant. The control variables of lifetime offending and opportunity to offend were added to the model, with the latter being partialled from the observed measures of official offending at each time point. Growth parameters were allowed to correlate, and a single covariance was estimated between opportunity to offend and the intercept for official offending. To model covariance in the residuals of concurrent measures, official offending was regressed on concurrent measures of moral disengagement and vice versa. (Regression paths are used instead of correlations because covariances between binary and continuous variables cannot be specified in Mplus.) Means were estimated for all observed control variables and for all latent growth parameters except the intercept of official offending, which was fixed at zero. This model is illustrated in Figure 4.

This model had good fit, $\chi^{2}(169)=339.44, p<.001$; CFI $=$ .95 ; $\mathrm{RMSEA}=.029(.025-.034)$, and revealed significant corre- lations between some of the growth parameters for moral disengagement and official offending (see Table 4). Most importantly, the slopes were correlated $(r=.27, p<.05)$, meaning that as one variable declined, so did the other. ${ }^{4}$ However, after accounting for the correlations between the growth parameters, no additional covariance was detected between the residuals for the repeated measures of moral disengagement and offending. Neither the estimated effect of offending on concurrent moral disengagement nor of moral disengagement on concurrent offending differed significantly from zero. Though these results do not constitute evidence of a causal relation between moral disengagement and official record of offending, the significant correlation between the slope estimates suggests a statistical relation between moral dis-

\footnotetext{
${ }^{4}$ Also, the intercept (at 6 months) for offending was correlated inversely with the slope $(r=-.25, p<.05)$ and directly with the quadratic term $(r=$ $.25, p<.05$ ) of moral disengagement, meaning that those more likely to be arrested at that time point tended to have a different shape to their trajectory change over time in moral disengagement. However, correlations with intercept terms are unreliable because they vary depending upon where (in time) one sets the intercept (Rogosa \& Willet, 1985).
} 


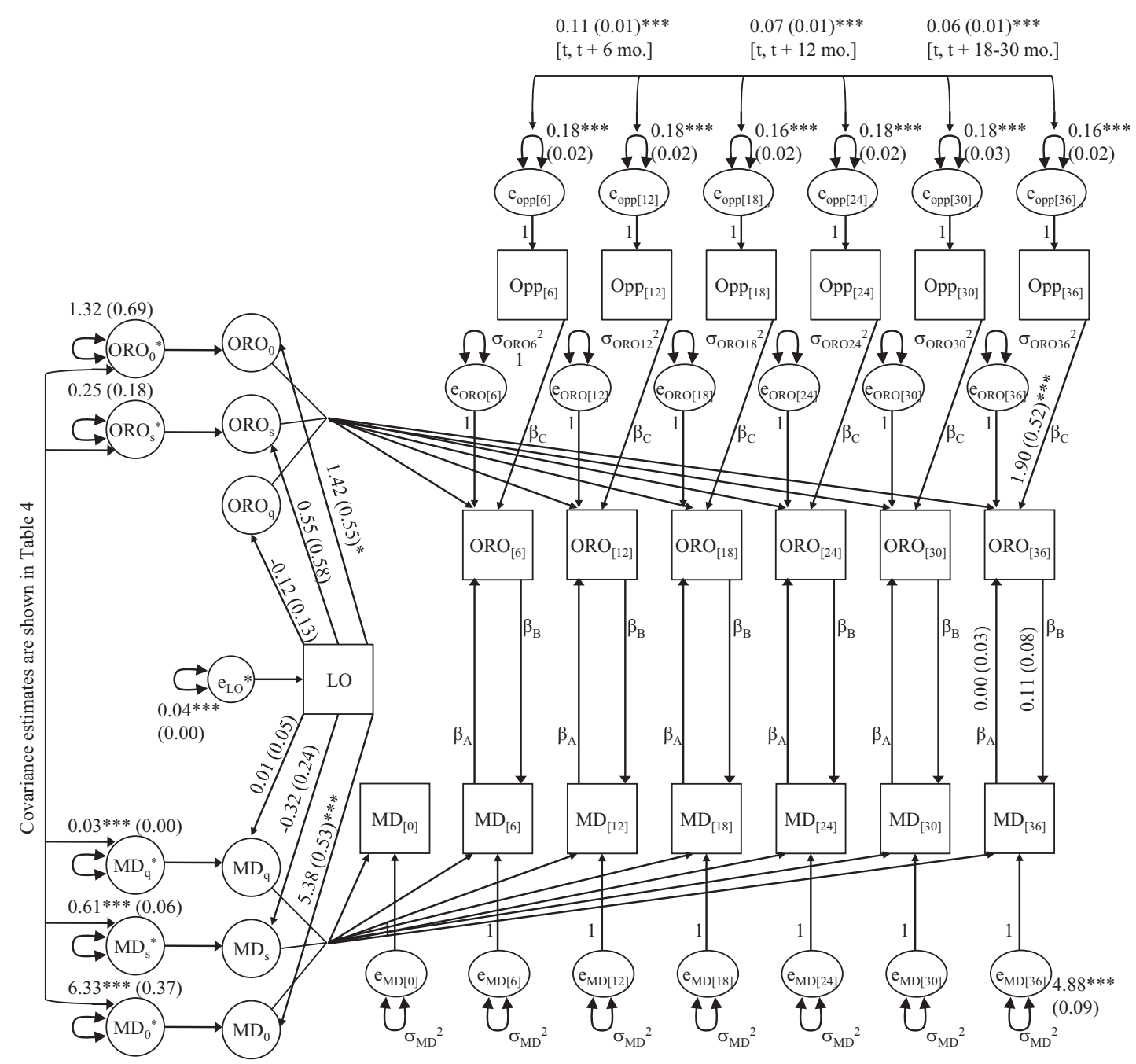

Figure 4. Bivariate latent growth curve model of moral disengagement (MD) and official record of offending (ORO), controlling for opportunity to offend (Opp) and lifetime offending (LO). Unstandardized estimates are shown. For simplicity, shorthand is used to represent the relations between the growth parameters (intercept [0], slope [s], and quadratic [q]) and the observed measures of moral disengagement and official record of offending. Parameters with the same name are constrained to be equal. Residual variance estimates $\sigma_{\mathrm{ORO} 2^{2}}$ through $\sigma_{\mathrm{ORO} 36}^{2}$ did not differ from zero. Not shown is the covariance between the intercept of ORO and the repeated measures of Opp. ${ }^{*} p<.05 .{ }^{* *} p<.01 .{ }^{* * *} p<.001$.

engagement and offending that cannot be attributed to shared method variance.

Regarding the effects of the control variables, official offending was more likely among those with greater opportunity to offend. Also, lifetime offending was directly related to the intercepts of official record and moral disengagement but not to the other growth parameters.

\section{Discussion}

Are morally disengaged attitudes a cause, a consequence, or a mere correlate of offending among delinquent youth? Our findings provide evidence for these attitudes being both correlated with and predictive of offending. As both moral disengagement and offending tend to decline over time in this sample, it is more accurate to say that, controlling for history of offending and time spent in secure confinement, becoming less tolerant of moral violations helps delinquent youth desist from antisocial behavior. While a nonexperimental study cannot provide definitive evidence of causality, our use of a model that accounts for correlations in the concurrent measures and developmental patterns of both variables while estimating the longitudinal relations between the two provides reasonable evidence of influence (McArdle, 2009). The size of this effect is substantial; it translates to a 1.14 standard deviation decline (on average) in log offending over a given 6-month period for every standard deviation decrease in moral disengagement at its start. Furthermore, this longitudinal relation persists even after accounting for the significant effects of callousness on both moral disengagement and self-reported offending. Our finding that 
Table 4

Estimated Covariances Among the Growth Parameters for Official Record of Offending (ORO) and Moral Disengagement (MD)

\begin{tabular}{|c|c|c|c|c|c|}
\hline Variable 1 & Variable 2 & $B$ & CI lower & CI upper & $r_{\mathrm{p}}$ \\
\hline \multirow[t]{4}{*}{ ORO intercept } & ORO slope & -0.176 & -0.450 & 0.098 & -0.233 \\
\hline & MD intercept & -0.179 & -0.755 & 0.397 & 0.048 \\
\hline & MD slope & -0.210 & -0.397 & -0.024 & $-0.248^{*}$ \\
\hline & MD quadratic & 0.048 & 0.004 & 0.093 & $0.252^{*}$ \\
\hline \multirow[t]{3}{*}{ ORO slope } & MD intercept & 0.127 & -0.073 & 0.328 & 0.183 \\
\hline & MD slope & 0.116 & 0.013 & 0.219 & $0.270^{*}$ \\
\hline & MD quadratic & -0.022 & -0.045 & 0.000 & -0.265 \\
\hline \multirow[t]{2}{*}{ MD intercept } & MD slope & 0.318 & 0.095 & 0.541 & $0.112^{* *}$ \\
\hline & MD quadratic & -0.122 & -0.173 & -0.071 & $-0.266^{\text {***** }}$ \\
\hline MD slope & MD quadratic & -0.110 & -0.136 & -0.084 & $-0.862^{* * * *}$ \\
\hline
\end{tabular}

${ }^{*} p<.05 . \quad{ }^{* * *} p<.01 .^{* * *} p<.001$.

change in moral disengagement is also associated with change in official record of offending provides some assurance that the study's main findings are not a result of shared method variance. Thus, we conclude that attitudes toward wrongdoing seem to play a role in juvenile offenders' desistance from antisocial behavior.

However, these attitudes are a moving target. Our study also demonstrates that moral disengagement tends to decline over time in this sample. Whether this decline is indicative of developmental change is not something that we can determine from these data. Prior research suggests that moral disengagement declines between adolescence and early adulthood in normative samples of adolescents (Paciello et al., 2008). Although our sample spanned this age range, our preliminary models did not identify age differences in the levels or patterns of change in moral disengagement. If the decline in moral disengagement were developmental, we would have expected the younger participants to exhibit higher levels of moral disengagement than the older participants.

The failure to find this developmental pattern is not, however, evidence that delinquent youth are less subject than their nondelinquent peers to developmental processes that might influence change in moral disengagement. To test this, one would need to sample randomly from a population of delinquent youth. The sample selection in the present study was not random; youths were enrolled soon after being convicted (or adjudicated guilty) of a felony offense. Given the association between moral disengagement and antisocial behavior, this likely resulted in youths being enrolled during a peak point in their personal developmental trajectories of moral disengagement. If this were the case, then the pattern of decline in moral disengagement could reflect normative psychosocial maturational processes, such as increased selfefficacy and self-regulatory capacity, which have been used to explain developmental decreases in moral disengagement in community samples of adolescents (Paciello et al., 2008). Another interesting possibility is that changes in participants' social contexts, perhaps even as a result of the justice system's response to the youths' crimes, account for this decline in moral disengagement. Understanding what contributes to this change in delinquent youths' attitudes toward wrongdoing is a worthwhile aim for future studies. Already, some research suggests that social contextual factors such as parenting style and neighborhood conditions may influence moral disengagement (Hyde et al., 2010; Pelton et al., 2004). Regardless of its cause, this decline in moral disengage- ment may be one reason (among many) why a large proportion of youth in the sample desist from offending (Mulvey et al., 2010).

An unexpected finding emerging from the analysis is that the estimated impact of self-reported offending on change in moral disengagement is inverse. That is, higher levels of offending portend decreases in moral disengagement. The size of this effect, however, is relatively small —an average 0.25 standard deviation decrease in moral disengagement for every one standard deviation increase in log offending. The notion that offending would lead to greater sensitivity to moral violations is contrary to extant theory and literature on the relations between attitudes toward crime and engagement in it (e.g., Barriga \& Gibbs, 1996; Gibbs, 1991; Guerra, Huesmann, \& Hanish, 1994; Hirschi, 1969; Huesmann \& Guerra, 1997), which views these processes as mutually reinforcing. Although other factors that were not accounted for in this study might explain this finding, we are hesitant to draw too much attention to it because of its peculiarity and small size; thus, further research is needed to sort this finding out. Nevertheless, it is important to bear in mind that our findings indicate that concurrent measures of moral disengagement and offending are positively correlated.

Consistent with our theory that callousness would encourage tolerant attitudes toward wrongdoing and facilitate offending, CU traits were strongly correlated with moral disengagement and moderately correlated with self-reported offending. However, our findings do not indicate that callousness serves as a confound on the longitudinal relations between moral disengagement and offending. Even after partialling callousness from each measure of the other two constructs and allowing its growth parameters to be correlated with those of moral disengagement and offending, the longitudinal relations between moral disengagement and offending remain largely unaltered. This finding suggests that the contribution of callousness to antisocial behavior is distinct from that of moral disengagement, in spite of the association between these variables. Thus, the results support the idea that morally disengaged attitudes can emerge from two discrete sources: (a) a history of disengaging internal sanctions or (b) emotional dysfunction. To the extent they reflect the former, morally disengaged attitudes are predictive of antisocial behavior.

Additionally, it is worth noting that callousness, which, as mentioned previously, shows evidence in other studies of having a considerable biological basis, was no more stable across the 3-year 
follow-up than moral disengagement, which is posited to emerge from experiential factors (Bandura, 1991). If anything, callousness appeared to be slightly less stable and, like moral disengagement, it tended to decline over time. Thus, at least some of the youth in the study who showed symptoms of callousness early in the study do not appear to be incapable of experiencing social emotions. Instead, their apparent emotional dysfunction early on may have been a response to their recent experiences-including commitment of a felony offense, reactions of friends and family to the act, and subsequent interaction with the justice system. As discussed by Frick and White (2008), stability in a characteristic (be it callousness or moral disengagement) does not necessarily imply biological determinism or implacability. It could, instead reflect stability in the social contextual factors that support the characteristic. Therefore, the levels of stability in callousness and moral disengagement do not provide insight into the degree to which these dispositions reflect genetic predispositions or responses to the environment, or how much they might be alterable through intervention.

This study has several strengths, including its large sample size, longitudinal design, and high retention rate. The use of a large, multisite sample of juvenile offenders reduces the risk of finding regionally specific relations among key variables. Also, our use of an LCS approach to the analysis enabled us to directly model our hypotheses about the dynamic relations over time between moral disengagement and self-reported offending. Though the official records of offending did not provide enough information for us to employ the same model as we used to analyze self-reported offending, we were able to confirm that our two sources of offending information were statistically related and that moral disengagement was associated with both. Nevertheless, caution should be used in interpreting the results. One caveat is that the results from the LCS models may be inflated due to shared method variance. Another is that the analyses do not account for the effects of treatment services youth may have received subsequent to adjudication. In addition, we did not control for other potentially important factors (e.g., variation in youth's social contexts, such as residence, school, employment, or peer groups). Future studies may want to account for these factors in order to provide a more complete picture of moral disengagement and its relation to behavior among delinquent youth. Also, the role of opportunity to offend could be explored in greater depth in future research by incorporating this measure into the dynamic systems model (along with moral disengagement and offending) rather than treating it as a covariate of offending.

In conclusion, moral disengagement appears to serve as a leading indicator of change in antisocial conduct among adolescent offenders. Reduction over time in moral disengagement may therefore help explain why most adolescent offenders "recover" from crime rather than become lifelong criminals. Future studies should investigate the causes of change in moral disengagement in delinquent male populations. In particular, this research should explore the impact of environmental factors (e.g., neighborhood and peer context) and specific experiences (e.g., incarceration, parenthood, employment) on moral disengagement. It would also be useful investigate whether the same patterns hold for female offenders and whether interventions that target moral disengagement might be effective in reducing recidivism.

\section{References}

Andershed, H., Kerr, M., Stattin, H., \& Levander, S. (2002). Psychopathic traits in non-referred youths: A new assessment tool. In E. Blauuw \& L. Sheridan (Eds.), Psychopaths: Current international perspectives (pp. 131-158). The Hague, the Netherlands: Elsevier.

Bandura, A. (1986). Social foundations of thought and action: A social cognitive theory. Englewood Cliffs, NJ: Prentice-Hall.

Bandura, A. (1991). Social cognitive theory of moral thought and action. In W. M. Kurtines \& J. L. Gewirtz (Eds.), Handbook of moral behavior and development (Vol. 1, pp. 45-103). Hillsdale, NJ: Erlbaum.

Bandura, A. (1999). Moral disengagement in the perpetration of inhumanities. Personality and Social Psychology Review, 3, 193-209. doi: 10.1207/s15327957pspr0303_3

Bandura, A., Barbaranelli, C., Caprara, G. V., \& Pastorelli, C. (1996). Mechanisms of moral disengagement in the exercise of moral agency. Journal of Personality and Social Psychology, 71, 364-374. doi: 10.1037/0022-3514.71.2.364

Bandura, A., Caprara, G. V., Barbaranelli, C., Pastorelli, C., \& Regalia, C. (2001). Sociocognitive self-regulatory mechanisms governing transgressive behavior. Journal of Personality and Social Psychology, 80, 125135. doi:10.1037/0022-3514.80.1.125

Barriga, A. Q., \& Gibbs, J. C. (1996). Measuring cognitive distortion in antisocial youth: Development and preliminary validation of the "How I Think" questionnaire. Aggressive Behavior, 22, 333-343. doi:10.1002/(SICI)1098-2337(1996)22:5<333::AID-AB2>3.0.CO;2-K

Barriga, A. Q., Morrison, E. M., Liau, A. K., \& Gibbs, J. C. (2001). Moral cognition: Explaining the gender difference in antisocial behavior. Merrill-Palmer Quarterly, 47, 532-562. doi:10.1353/mpq.2001.0020

Blair, R. J. R. (2007). The amygdala and ventromedial prefrontal cortex in morality and psychopathy. Trends in Cognitive Sciences, 11, 387-392. doi:10.1016/j.tics.2007.07.003

Brame, R., Fagan, J., Piquero, A., Schubert, C., \& Steinberg, L. (2004). Criminal careers of serious delinquents in two cities. Youth Violence and Juvenile Justice, 2, 256-272. doi:10.1177/1541204004265877

Caputo, A. A., Frick, P. J., \& Brodsky, S. L. (1999). Family violence and juvenile sex offending: The potential mediating role of psychopathic traits and negative attitudes toward women. Criminal Justice and Behavior, 26, 338-356. doi:10.1177/0093854899026003004

Cauffman, E., Kimonis, E. R., Dmitrieva, J., \& Monahan, K. C. (2009). A multimethod assessment of juvenile psychopathy: Comparing the predictive utility of the PCL:YV, YPI, and NEO PRI. Psychological Assessment, 21, 528-542. doi:10.1037/a0017367

Christian, R. E., Frick, P. J., Hill, N. L., Tyler, L., \& Frazer, D. R. (1997). Psychopathy and conduct problems in children: II. Implications for subtyping children with conduct problems. Journal of the American Academy of Child \& Adolescent Psychiatry, 36, 233-241. doi:10.1097/ 00004583-199702000-00014

Dienstbier, R. A. (1984). The role of emotion in moral socialization. In C. Izard, J. Kagan, \& R. B. Zajonc (Eds.), Emotions, cognition, and behavior (pp. 484-518). New York, NY: Cambridge University Press.

Dunford, F. W., \& Elliott, D. S. (1984). Identifying career offenders using self-reported data. Journal of Research in Crime and Delinquency, 21, 57-86. doi: $10.1177 / 0022427884021001004$

Frick, P. J., \& White, S. F. (2008). The importance of callous-unemotional traits for developmental models of aggressive and antisocial behavior. Journal of Child Psychology and Psychiatry, 49, 359-375. doi:10.1111/ j.1469-7610.2007.01862.x

Gibbs, J. C. (1991). Sociomoral developmental delay and cognitive distortion: Implications for the treatment of antisocial youth. In W. M. Kurtines \& J. L. Gewirtz (Eds.), Handbook of moral behavior and development (Vol. 3, pp. 95-110). Hillsdale, NJ: Erlbaum.

Gini, G. (2006). Social cognition and moral cognition in bullying: What's wrong? Aggressive Behavior, 32, 528-539. doi:10.1002/ab.20153

Guerra, N. G., Huesmann, L. R., \& Hanish, L. (1994). The role of 
normative beliefs in children's social behavior. In N. Eisenberg (Ed.), Review of personality and social psychology, development and social psychology: The interface (pp. 140-158). London, England: Sage.

Hirschi, T. (1969). Causes of delinquency. Berkeley: University of California Press.

Hirschi, T., \& Gottfredson, M. (1983). Age and the explanation of crime. American Journal of Sociology, 89, 552-584. doi:10.1086/227905

Huesmann, L. R., \& Guerra, N. G. (1997). Children's normative beliefs about aggression and aggressive behavior. Journal of Personality and Social Psychology, 72, 408-419. doi:10.1037/0022-3514.72.2.408

Huizinga, D., Esbensen, F. A., \& Weiher, A. W. (1991). Are there multiple paths to delinquency? Journal of Criminal Law and Criminology, 82, 83-118. doi:10.2307/1143790

Hyde, L. W., Shaw, D. S., \& Moilanen, K. L. (2010). Developmental precursors of moral disengagement and the role of moral disengagement in the development of antisocial behavior. Journal of Abnormal Child Psychology, 38, 197-209. doi:10.1007/s10802-009-9358-5

Hymel, S., Rocke-Henderson, N., \& Bonanno, R. A. (2005). Moral disengagement: A framework for understanding bullying among adolescents. Journal of Social Sciences, 8, 1-11.

Kiriakidis, S. P. (2008). Moral disengagement: Relation to delinquency and independence from indices of social dysfunction. International Journal of Offender Therapy and Comparative Criminology, 52, 571-583. doi: 10.1177/0306624X07309063

Knight, G. P., Little, M., Losoya, S. H., \& Mulvey, E. P. (2004). The Self-Report of Offending among serious juvenile offenders: Crossgender, cross-ethnic/race measurement. Youth Violence and Juvenile Justice, 2, 273-295. doi:10.1177/1541204004265878

Kochanska, G. (1991). Socialization and temperament in the development of guilt and conscience. Child Development, 62, 1379-1392. doi: $10.2307 / 1130813$

Kohlberg, L., \& Gilligan, C. (1971). The adolescent as a philosopher: The discovery of the self in a postconventional world. Daedalus, 100, 10511086.

Larsson, H., Andershed, H., \& Lichtenstein, P. (2006). A genetic factor explains most of the variation in the psychopathic personality. Journal of Abnormal Psychology, 115, 221-230. doi:10.1037/0021843X.115.2.221

Laub, J. H., \& Sampson, R. J. (2001). Understanding desistance from crime. In Tonry, M. (Ed.), Crime and justice: A review of research (Vol. 28, pp. 1-70). Chicago, IL: University of Chicago Press.

Maruna, S., \& Copes, H. (2005). What have we learned from five decades of neutralization research? Crime and Justice, 32, 221-320. doi:01923234/2005/0032-0004

McArdle, J. J. (2009). Latent variable modeling of differences and changes with longitudinal data. Annual Review of Psychology, 60, 577-605. doi:10.1146/annurev.psych.60.110707.163612

McArdle, J. J., \& Hamagami, F. (2001). Linear dynamic analyses of incomplete longitudinal data. In L. Collins \& A. Sayer (Eds.), New methods for the analysis of change (pp. 137-176). Washington, DC: APA Press.

McArdle, J. J., \& Hamagami, F. (2004). Models for dynamic change hypotheses. In K. van Montfort, J. Oud, \& A. Satorra (Eds.), Recent developments on structural equation models: Theory and applications (pp. 295-336). Amsterdam, the Netherlands: Kluwer.

Mulvey, E. P., Steinberg, L., Fagan, J., Cauffman, E., Piquero, A. R., Chassin, L., . . Losoya, S. H. (2004). Theory and research on desistance from antisocial activity among serious adolescent offenders. Youth $\mathrm{Vi}$ olence and Juvenile Justice, 2, 213-236. doi:10.1177/ 1541204004265864

Mulvey, E. P., Steinberg, L., Piquero, A. R., Besana, M., Fagan, J., Schubert, C., \& Cauffman, E. (2010). Trajectories of desistance and continuity in antisocial behavior following court adjudication among serious adolescent offenders. Development and Psychopathology, 22, 453-475. doi:10.1017/S0954579410000179

Muthén, L. K., \& Muthén, B. O. (2009). MPlus user's guide (5th ed.). Los Angeles, CA: Muthén \& Muthén.

O'Brien, B. S., \& Frick, P. J. (1996). Reward dominance: Associations with anxiety, conduct problems, and psychopathy in children. Journal of Abnormal Child Psychology, 24, 223-240. doi:10.1007/BF01441486

Oxford, M., Cavell, T. A., \& Hughes, J. N. (2003). Callous/unemotional traits moderate the relation between ineffective parenting and child externalizing problems: A partial replication and extension. Journal of Clinical Child and Adolescent Psychology, 32, 577-585. doi:10.1207/ S15374424JCCP3204_10

Paciello, M., Fida, R., Tramontano, C., Lupinetti, C., \& Caprara, G. V. (2008). Stability and change of moral disengagement and its impact on aggression and violence in late adolescence. Child Development, 79, 1288-1309. doi:10.1111/j.1467-8624.2008.01189.x

Pardini, D. A., Lochman, J. E., \& Frick, P. J. (2003). Callous/unemotional traits and social-cognitive processes in adjudicated youths. Journal of the American Academy of Child \& Adolescent Psychiatry, 42, 364-371. doi:10.1097/00004583-200303000-00018

Pelton, J., Gound, M., Forehand, R., \& Brody, G. (2004). The Moral Disengagement Scale: Extension with an American minority sample. Journal of Psychopathology and Behavioral Assessment, 26, 31-39. doi:10.1023/B:JOBA.0000007454.34707.a5

Piquero, A. R. (2008). Taking stock of developmental trajectories of criminal activity over the life course. In A. Liberman (Ed.), The long view of crime: A synthesis of longitudinal research (pp. 23-78). New York, NY: Springer. doi:10.1007/978-0-387-71165-2

Piquero, A. R., Blumstein, A., Brame, R., Haapanen, R., Mulvey, E. P., \& Nagin, D. S. (2001). Assessing the impact of exposure time and incapacitation on longitudinal trajectories of criminal offending. Journal of Adolescent Research, 16, 54-74. doi:10.1177/0743558401161005

Piquero, A. R., Farrington, D. P., \& Blumstein, A. (2003). The criminal career paradigm. In M. Tonry (Ed.), Crime and justice: A review of research (Vol. 30, pp. 359-506). Chicago, IL: University of Chicago Press.

Rogosa, D., \& Willett, J. B. (1985). Understanding correlates of change by modeling individual differences in growth. Psychometrika, 50, 203-228.

Salekin, R. T., \& Frick, P. J. (2005). Psychopathy in children and adolescents: The need for a developmental perspective. Journal of Abnormal Child Psychology, 33, 403-409. doi:10.1007/s10802-005-5722-2

Schubert, C. A., Mulvey, E. P., Steinberg, L., Cauffman, E., Losoya, S. H., Hecker, T., ... Knight, G. P. (2004). Operational lessons from the pathways to desistance project. Youth Violence and Juvenile Justice, 2, 237-255. doi:10.1177/1541204004265875

Skeem, J. L., \& Cauffman, E. (2003). Views of the downward extension: Comparing the youth version of the Psychopathy Checklist with the Youth Psychopathic Traits Inventory. Behavioral Sciences \& the Law, 21, 737-770. doi:10.1002/bsl.563

Sykes, G. M., \& Matza, D. (1957). Techniques of neutralization: A theory of delinquency. American Sociological Review, 22, 664-670.

Taylor, J., Loney, B. R., Bobadilla, L. Iacono, W. G., \& McGue, M. (2003). Genetic and environmental influences on psychopathy trait dimensions in a community sample of male twins. Journal of Abnormal Child Psychology, 31, 633-645. doi:10.1023/A:1026262207449

Wootton, J. M., Frick, P. J., Shelton, K. K., \& Silverthorn, P. (1997). Ineffective parenting and childhood conduct problems: The moderating role of callous-unemotional traits. Journal of Consulting and Clinical Psychology, 65, 301-308. doi:10.1037/0022-006X.65.2.292.b

Received August 10, 2010

Revision received May 27, 2011 Accepted June 9, 2011 